\section{A retrospective study for Colorectal Cancer in Vlore, Albania-suggestions for further implications}

\author{
Fatjona Kamberi* and Jerina Jaho \\ Research Center of Public Health, Faculty of Public Health, University of Vlore "Ismail Qemali", \\ Vlore, Albania
}

\section{Abstract}

Objective: Colorectal cancer is one of the most commonly occurring cancers in men and women worldwide as well as one of the most common causes of death from cancer. It has a higher prevalence in men than women. The treatment of colorectal cancer (surgically or through chemotherapy) severely affects both patients and their families. The objective of the study was to identify cases of colorectal cancer, evaluate their demographic and clinical data, and identify any statistical relationship.

Methods: This is a retrospective study. The data were collected through the revision of cancer patients' files in the Chemotherapy Center at Vlore Regional Hospital, Vlore, Albania. The analysis included files from 2015-March 2019. A total of 72 patients' files with colorectal cancer were analyzed.

Result: Mean age of patients $66.36 \pm$ SD10.99 years old, range 38-86. Most of the patients were male $(n=45)$ and with colon cancer type $(n=44) .19$ patients had treatment with surgery, radiation, and chemotherapy. $56.34 \%$ of patients with colorectal cancer are still alive. The results of the study are the same as the global trend in terms of age, gender, type of cancer but not in terms of years of survival, which appear lower.

Conclusion: The study suggests that in demographic terms patients with colorectal cancer have no difference from world trend. There was also a marked lack of documentation regarding the clinical data of patients. The complete and accurate documentation of cases with colorectal cancer is recommended to develop quality models of nursing care as well as to design effective promotional and preventive campaigns for colorectal cancer.

\section{More Information}

*Address for Correspondence: Fatjona Kamberi, Research Center of Public Health, Faculty of Public Health, University of Vlore "Ismail Qemali", Vlore, Albania, Tel: +355 692055 934; Email: fatjona.kamberi@univlora.edu.al; fatjonakamberi@gmail.com

Submitted: 12 February 2020

Approved: 24 February 2020 Published: 25 February 2020

How to cite this article: Kamberi F, Jaho J. A retrospective study for Colorectal Cancer in Vlore, Albania-suggestions for further implications. Arch Cancer Sci Ther. 2020; 4: 003-006.

DOI: $10.29328 /$ journal.acst. 1001013

ORCiD: orcid.org/0000-0003-4793-9384

Copyright: $\odot 2020$ Kamberi F, et al. This is an open access article distributed under the Creative Commons Attribution License, which permits unrestricted use, distribution, and reproduction in any medium, provided the original work is properly cited.

Keywords: Colorectal cancer; Prevention; Chemotherapy; Nursing care; Survival rate

Check for updates

OPEN ACCESS

\section{Introduction}

Colorectal cancer is one of the most commonly occurring cancers in men and women worldwide as well as one of the most common causes of death from cancer [1]. Due to exogenous and/or endogenous factors, the mortality of colorectal cancer is higher in men than women [2]. Colorectal cancer mainly affects older adults, but the incidence is rising among the young population [3]. Also, in Europe the incidence of colorectal cancer is rising among young adults, stressing the importance of taking into account the review of screening guidelines [4]. Survival for patients with colorectal cancer has improved over the past decades especially for young patients, while older patients aged $\geq 85$ years benefited less [5]. Survival depends on the stage at which it is diagnosed, with early-stage diagnosis ensuring survival for at least 5 years from when the cancer is found [6]. In addition, gender is a significant factor in influencing survival results among colorectal cancer patients, females had significantly better survival rates than men [7]. According to World Health Organization, a good part of cancer deaths is due to behavioral and dietary risks such as lack of physical activity, tobacco and alcohol use, obesity, and low fruit and vegetable intake [6]. The increased risk of colorectal cancer is significantly associated with a high intake of red and processed meat [8], while the risk for colorectal cancer decreases with a high intake of dietary fiber [9]. The treatment of colorectal cancer usually includes or combines methods such as surgery, radiation therapy, and chemotherapy. The treatment chosen is based on the stage of colorectal cancer when diagnosed and usually, the first treatment is surgery. If the treatment does not work, in particular in advanced stages of colorectal cancer the disease is considered terminal and may need hospice care for both the patient and family [10]. Primary prevention based on modifications in diet and lifestyle, increasing physical activity with a focus on weight loss reduces the risk of colorectal cancer [11]. In addition, 
secondary prevention reduces the number of incident cases through early detection of cancer at a curable stage. This is achieved by organizing population-based screening interventions and is particularly necessary for developing countries [12]. Nurses, as an important part of health care staff, having knowledge of and using evidence-based guidelines, screening for colorectal cancer, can influence in decreasing the morbidity and mortality associated with colorectal cancer [13]. In addition, the collaboration of both the oncology care team (including nurses and pharmacists) and patients is crucial for effective side effect management of chemotherapy for colorectal cancer [14]. In addition, providing customized chemotherapy with maximum benefits and fewer side effects is not yet possible [15].

\section{Materials and methods}

\section{Study design and population}

A retrospective study was conducted to identify all patients with colorectal cancer through the examination of the patients' files treated at the Chemotherapy Center at Vlore Regional Hospital, Vlore, Albania. The objective of the study, besides identifying cases of colorectal cancer, gender and, the mean age of affected patients, was the assessment of the statistical relationship between the type of treatment received after being diagnosed with colorectal cancer and the progress of health status. Another objective was to identify case documentation in terms of disease history, risk factors, chemotherapy side effects, and their management.

\section{Data collection}

The data were collected through the revision of the cancer patients' files in the Chemotherapy Center at Vlore Regional Hospital, Vlore, Albania. A medical diagnosis of colorectal cancer was the criteria for inclusion in the study. Patients diagnosed with other, non-colorectal, types of cancer were excluded from the study. Files from 2015-March 2019 were analyzed. The duration of the data collection lasted from January to March 2019. In total 72 patients with colorectal cancer were identified. The Chemotherapy Center in the Vlore Regional Hospital was set up in January 2015. This center offers chemotherapy to patients and gathers data on their condition. The data collected are demographics such as age, gender as well as clinical data like the type of cancer diagnosed, the type of treatment received after being diagnosed with cancer, the progress of the health status, and whether the patients were still alive or not. However, the patient files had no documented data on the complications of colorectal cancer, the type of surgical treatment applied, and the stage of cancer at the time of diagnosis.

\section{Ethical considerations}

An approval to conduct the study was obtained by the relevant ethics committee. The study guide based on the principles of the Helsinki Declaration [16] and of the Ethics for researchers Facilitating Research Excellence in FP7 [17]. Also, anonymity was assured at all stages of the study.

\section{Data analysis}

Statistical analysis was performed using Epi-InfoTM 7 software version 7.1.3.10 (CD-C Epi InfoTM). Descriptive statistics was used and significance was set at level $\leqslant 0.05$. Demographics and outcome variables were summarized using descriptive statistics, expressed as mean, Standard Deviation (SD) for continuous variables and percent for categorical variables.

\section{Results}

\section{Participant's characteristics}

A total of 72 patient files were analyzed. Of the 72 cases, $62.50 \%(n=45)$ were male, with the most predominant age being 68 years old. The mean age of the patients was 66.36 years old. Colon cancer predominated with $62.50 \%$. The treatment was mainly surgical $(n=48 ; 66.67 \%)$ and radiotherapy ( $n=$ $49 ; 68.06 \%$ ). Only 19 patients out of 72 had been treated with a combination of surgery, chemotherapy, and radiotherapy. $56.34 \%$ of patients were still alive (Table 1 ).

No statistical relationship was found between treatment and the progress of health status, gender and the progress of health status, $p>0.05$.

Distribution of patients by gender based on the type of treatment of colorectal cancer.

Table 2 shows the distribution of patients based on the type of treatment of colorectal cancer. The treatments received were surgery, chemotherapy, and radiotherapy. There were 27 female patients and 45 male patients.

It should be noted that apart from the data presented in table 1 and table 2, no patient data was documented regarding the history of the disease, risk factors, and chemotherapy side effects management.

\begin{tabular}{|c|c|c|c|c|}
\hline \multicolumn{5}{|c|}{ Demographic data } \\
\hline \multirow{2}{*}{ Age (years) } & Mean \pm SDa & $66.36 \pm 10.99$ & Media $n=68$ & Mode $=68$ \\
\hline & Range & $38-86$ & & \\
\hline $\begin{array}{l}\text { Gender } \\
\text { Male } \\
\text { Females }\end{array}$ & $\begin{array}{l}N \\
45 \\
27\end{array}$ & $\begin{array}{l}(\%) \\
62.50 \\
37.50\end{array}$ & $\begin{array}{c}\text { Exact } 95 \% \mathrm{LCL}^{\mathrm{b}} \\
50.30 \\
26.36\end{array}$ & $\begin{array}{c}\text { Exact } 95 \% \mathrm{UCL}^{\mathrm{c}} \\
73.64 \\
49.70\end{array}$ \\
\hline \multicolumn{5}{|c|}{ Clinical data } \\
\hline $\begin{array}{l}\text { Type of cancer } \\
\text { Colon cancer } \\
\text { Rectal cancer }\end{array}$ & $\begin{array}{l}N \\
44 \\
26\end{array}$ & $\begin{array}{c}(\%) \\
62.86 \\
37.14\end{array}$ & $\begin{array}{c}\text { Exact } 95 \% \mathrm{LCL} \\
50.48 \\
25.89\end{array}$ & $\begin{array}{c}\text { Exact } 95 \% \mathrm{UCL} \\
74.11 \\
49.52\end{array}$ \\
\hline \multirow{2}{*}{ Treatment } & \multicolumn{2}{|c|}{ Yes } & \multicolumn{2}{|c|}{ No } \\
\hline & $\mathrm{N}$ & $(\%)$ & $\mathrm{N}$ & $(\%)$ \\
\hline $\begin{array}{c}\text { Surgery } \\
\text { Chemotherapy } \\
\text { Radiotherapy }\end{array}$ & $\begin{array}{l}48 \\
19 \\
49\end{array}$ & $\begin{array}{l}66.67 \\
27.94 \\
68.06\end{array}$ & $\begin{array}{l}24 \\
49 \\
23\end{array}$ & $\begin{array}{l}(33.33) \\
72.06 \\
31.94\end{array}$ \\
\hline \multirow{2}{*}{$\begin{array}{l}\text { Progress of health } \\
\text { status }\end{array}$} & \multicolumn{2}{|c|}{ Yes } & \multicolumn{2}{|c|}{ No } \\
\hline & $\mathrm{N}$ & $(\%)$ & $\mathrm{N}$ & $(\%)$ \\
\hline Alive & 40 & 56.34 & 31 & 43.66 \\
\hline
\end{tabular}


Table 2: Distribution of patients based on the type of treatment of colorectal cancer by gender.

\begin{tabular}{|c|c|c|c|c|}
\hline $\begin{array}{c}\text { Type of treatment by } \\
\text { gender }\end{array}$ & Frequency & Percent & Exact 95\% LCL & Exact 95\% UCL \\
\hline $\begin{array}{c}\text { Surgery } \\
\text { Female 27 }\end{array}$ & 15 & 32.65 & 19.95 & 47.54 \\
\hline Male 45 & 33 & 67.35 & 52.46 & 80.05 \\
\hline $\begin{array}{c}\text { TOTAL } \\
\text { Chemotherapy }\end{array}$ & 48 & & & \\
\hline Female 27 & 6 & 31.58 & 12.58 & 56.55 \\
\hline Male 45 & 13 & 68.42 & 43.45 & 87.42 \\
\hline Total & 19 & & & \\
\hline Radiotherapy & & & & \\
\hline Female 27 & 14 & 28.57 & 16.58 & 43.26 \\
\hline Male 45 & 35 & 71.43 & 56.74 & 83.42 \\
\hline TOTAL & 49 & & & \\
\hline
\end{tabular}

\section{Discussion}

This study was set out with the aim to identify all patients with colorectal cancer in the Chemotherapy Center at Vlore Regional Hospital, as well as to evaluate the demographics and clinical data of patients identified. A total of 72 patients with colorectal cancer were identified from the opening of the chemotherapy center (January 2015) until March 2019. The mean age of patients diagnosed with colorectal cancer was 66.36 years old, median age 68 years old, Table 1 . The trends regarding the age of diagnosis for colorectal cancer in our study did not differ from global trends as the age of diagnosis is the same [18] despite the fact that over the past two decades there is an increase of incidence of colorectal cancer in young adults [19].

Even though colorectal cancer is one of the most common causes of cancer morbidity both in men and in women [1]. Table 1 shows that in the 72 patients with colorectal cancer analyzed in our study, 45 were men and 27 were women. A study suggests that women over 65 years old have higher mortality and lower 5-year survival rate of colorectal cancer compared to the same age-group of men [20]. On the other hand, a meta-analysis regarding gender differences in the survival rate of colorectal cancer found that gender is a significant factor and that females are the ones with more survival benefits. [21].

In our study, no statistical association was found between gender and survival rate. It should be emphasized that the patient charts lacked the exact period of diagnosis of the disease and that the assessment of the statistical association for survival after diagnosis was performed based on the prognosis of health status.

Refer to table 1, colon cancer is more prevalent than rectal cancer $(62.86 \%$ vs. $37.14 \%)$. The numbers are the same as the worldwide trend, with colon cancer being more prevalent [22].

As suggested by the literature, the treatment of colorectal cancer is based on and/or a combination of surgery, radiation, and chemotherapy [22]. Table 1 and Table 2 show that only 19 patients, female $n=6$ and male $n=13$ had the all three of the treatments mentioned above. 48 patients had surgery and radiation therapy while 49 patients had surgery and chemotherapy as treatment. Since the treatment of colorectal cancer is based on the stage of cancer when diagnosed. The first treatment is surgery [23], and it is mainly used in the early stages. The results of our study suggest that only 48 patients (female $n=15$ and male $n=33$ ) of 72 underwent surgery as treatment indicating that the rest of the patients have been diagnosed at an advanced stage (Table 2). Despite this fact, the above result requires further study as the patient charts did not have accurate data regarding the stage of colorectal cancer upon diagnosis. Regarding the progress of health status. Table 1 shows that only 40 patients with colorectal cancer are still alive, while 32 others have died. Although we do not have accurate data regarding the period of diagnosis of patients with colorectal cancer, referring to the period of the Chemotherapy center opening (January 2015) and the end of the study in March 2019, we can say that about 44\% of patients had the survival rate of fewer than 5 years. Referring to another study conducted in Albania for gastric cancer, the survival rate after the diagnosis was about two years [24]. The figures follow global trends [7,19]. Patients' files had no data on colorectal cancer risk factors and family history. The same problem was found regarding a retrospective study for the evidence of gastric cancer cases, year survival rate and frequent symptoms, where the clinical data were very limited [24]. The results of the study suggest more complete and accurate documentation of colorectal cancer patients, especially regarding the year of diagnosis, the exact age of diagnosis, the stage of diagnosis and risk factors is necessary. Complete documentation is also needed for the side effects of type treatment received. All of these will serve not only to design effective promotional and preventive campaigns for colorectal cancer but also to develop quality models of nursing care for colorectal cancer patients for better management of side effects related to chemotherapy.

\section{References}

1. Bray F, Ferlay J, Soerjomataram I, Siegel RL, Torre LA, et al. Global Cancer Statistics 2018: GLOBOCAN estimates of incidence and mortality worldwide for 36 cancers in 185 countries. CA Cancer J Clin. 2018; 68: 394-424.

PubMed: https://www.ncbi.nlm.nih.gov/pubmed/30207593

2. White A, Ironmonger L, Steele RJC, Ormiston-Smith N, Crawford C, et al. A review of sex-related differences in colorectal cancer incidence, screening uptake, routes to diagnosis, cancer stage and survival in the UK. BMC Cancer. 2018; 18: 906.

PubMed: https://www.ncbi.nlm.nih.gov/pubmed/30236083

3. ACS. American Cancer Society's (ACS) publication, Cancer Facts and Figures 2019, and the ACS website. 2019.

4. Feng Y, Mo S, Dai W, Li Q, Cai G, et al. Increasing age-related survival gap among patients with colorectal cancer: a population-based retrospective study. Int J Clin Oncol. 2019; 25: 100-109.

PubMed: https://www.ncbi.nlm.nih.gov/pubmed/31531787 
5. Vuik FE, Nieuwenburg SA, Bardou M, Lansdorp-Vogelaar I, Dinis-Ribeiro $\mathrm{M}$, et al. Increasing incidence of colorectal cancer in young adults in Europe over the last 25 years. Gut. 2019; 68: 1820-1826.

PubMed: https://www.ncbi.nlm.nih.gov/pubmed/31097539

6. WHO. Fact sheets Cancer. 2018.

7. Yang Y, Wang G, He J, Ren S, Wu F, Zhang J, et al. Gender differences in colorectal cancer survival: A meta-analysis. Int J Cancer. 2017; 141: 1942-1949.

PubMed: https://www.ncbi.nlm.nih.gov/pubmed/28599355

8. Chan DS, Lau R, Aune D, Vieira R, Greenwood DC, et al. Red and processed meat and colorectal cancer incidence: meta-analysis of prospective studies. PLoS One. 2011; 6: e20456.

PubMed: https://www.ncbi.nlm.nih.gov/pubmed/21674008

9. Aune D, Chan DS, Lau R, Vieira R, Greenwood DC, et al. Dietary fibre, whole grains, and risk of colorectal cancer: systematic review and dose-response meta-analysis of prospective studies. BMJ. 2011; 343: d6617.

PubMed: https://www.ncbi.nlm.nih.gov/pubmed/22074852

10. American Society of Clinical Oncology. (2018). Colorectal Cancer: Types of Treatment. Approved by the Cancer. 2018.

11. Chan AT, Giovannucci EL. Primary prevention of colorectal cancer. Gastroenterology. 2010; 138: 2029-2043.

PubMed: https://www.ncbi.nlm.nih.gov/pubmed/20420944

12. René Lambert. The Future of Colorectal Cancer Prevention in Developing Countries. E-WGN. 2013; 18.

13. Mahon SM. Colorectal cancer screening-Using evidence-based guidelines. Nurse Pract. 2017; 42: 18-26.

PubMed: https://www.ncbi.nlm.nih.gov/pubmed/28926493

14. Berg D. Managing the side effects of chemotherapy for colorectal cancer. Semin Oncol. 1998; 25: 53-59.

PubMed: https://www.ncbi.nlm.nih.gov/pubmed/9786317
15. Stoehlmacher J. Prediction of efficacy and side effects of chemotherapy in colorectal cancer. Recent Results Cancer Res. 2007; 176: 81-88. PubMed: https://www.ncbi.nlm.nih.gov/pubmed/17607918

16. World Medical Association. World Medical Association Declaration of Helsinki: ethical principles for medical research involving human subjects. JAMA. 2013; 310: 2191-2194.

PubMed: https://www.ncbi.nlm.nih.gov/pubmed/24141714

17. European Commission. Ethics for researchers Facilitating Research Excellence in FP7 Luxembourg: Publications Office of the European Union 2013 - II. 2013.

18. Colorectal Cancer Alliance. Colorectal cancer facts and figures. Statistics and risk factors. 2019.

19. Vuik FE, Nieuwenburg SA, Bardou M, Lansdorp-Vogelaar I, Dinis-Ribeiro $M$, et al. Increasing incidence of colorectal cancer in young adults in Europe over the last 25 years. Gut. 2019; 68: 1820-1826. PubMed: https://www.ncbi.nlm.nih.gov/pubmed/31097539

20. Kim SE, Paik HY, Yoon H, Lee JE, Kim N, et al. Sex- and gender-specific disparities in colorectal cancer risk. World J Gastroenterol. 2015; 21 : 5167-5175.

PubMed: https://www.ncbi.nlm.nih.gov/pubmed/25954090

21. Yang $Y$, Wang $G$, He J, Ren $S$, Wu F, et al. Gender differences in colorectal cancer survival: A meta-analysis. Int J Cancer. 2017; 141: 1942-1949. PubMed: https://www.ncbi.nlm.nih.gov/pubmed/28599355

22. American Society of Clinical Oncology. Colorectal Cancer: Statistics. Approved by the Cancer. 2018.

23. Papamichael D, Audisio RA, Glimelius B, de Gramont A, Glynne-Jones $\mathrm{R}$, et al. Treatment of colorectal cancer in older patients: International Society of Geriatric Oncology (SIOG) consensus recommendations 2013. Ann Oncol. 2015; 26: 463-476.

PubMed: https://www.ncbi.nlm.nih.gov/pubmed/25015334

24. Kamberi F, Çelaj J. Evidence of gastric cancer cases, year survival rate and frequent symptoms - A retrospective study at Vlora regional hospital, Albania. Cancer Reports and Reviews. 2018; 2: 1-4. 